\title{
O PROFESSOR UNIVERSITÁRIO PORTUGUÊS DO INÍCIO DO SÉCULO XX: O CASO PARADIGMÁTICO DE VICENTE GONÇALVES
}

\author{
Cecília Costa $^{1}$ \\ Universidade de Trás-os-Montes e Alto Douro - UTAD - Portugal
}

(aceito para publicação em novembro de 2016)

\begin{abstract}
Resumo
Em Portugal, o conceito de professor universitário de ciências matemáticas foi mudando ao longo do tempo, especialmente durante o século XX. Do professor universitário que apenas se dedicava à docência e que transmitia os conhecimentos clássicos; aquele que tem diversas vertentes a cumprir, como a de investigador, de autor, de gestor, de divulgador, etc.; encontramos casos de professores universitários que marcaram pela sua atuação profissional. Apresentamos o caso paradigmático do professor universitário português J. Vicente Gonçalves (1896-1985).
\end{abstract}

Palavras-chave: Matemática, História, Biografia, Vicente Gonçalves.

\section{[The PORTUGUESE UNIVERSITY PROFESSOR OF THE BEGINNING OF THE $20^{\mathrm{TH}}$ CENTURY:THE PARADIGM CASE OF VICENTE GONÇALVES]}

\begin{abstract}
In Portugal, the concept of the university math professor has changed over time, especially during the 20th century. From the university professor devoted only to teach and transmit the classical knowledge, till the one who has different roles to accomplish, as researcher, author, supervisor, etc., we find cases of university professors who marked by their
\end{abstract}

\footnotetext{
${ }^{1}$ Membro integrado do CIDTFF - Centro de Investigação Didática e Tecnologia na Formação de Formadores (Lab-DCT da UTAD) e membro colaborador do CIDMA - Centro de Investigação e Desenvolvimento Matemática e Aplicações (GHM), ambos da Universidade de Aveiro, Portugal.

Este trabalho é financiado por Fundos Nacionais através da FCT - Fundação para a Ciência e a Tecnologia no âmbito do projeto UID/CED/00194/2013.
} 
professional performance. We present the paradigm case of the Portuguese university math professor J. Vicente Gonçalves (1896-1985).

Keywords: Mathematics, History, Biography, Vicente Gonçalves.

\section{Introdução}

Nas primeiras três décadas do século XX, o modelo de professor universitário português (de ciências matemáticas) reduzia-se ao lente que reproduzia conhecimentos clássicos. Eventualmente produzia alguns textos, na maioria das vezes para provas académicas, de cariz mais compilador do que original (figura 1).

\section{DOCÊNCIA - - - - - - - - PUBLICAÇÃO}

Figura 1 - Modelo da atuação tipo do professor universitário português de matemática (primeiras três décadas do séc. XX)

Estudos históricos permitem perceber que sempre existiram vozes dissonantes desta postura, entre os professores universitários portugueses (Cosme \& Costa, 2015). A citação seguinte de Sidónio Paes (1872-1918):

"Temos de modificar totalmente os nossos processos de ensino e os nossos critérios de julgamento.

A preocupação do professor deve ser crear o gosto do alumno pelo trabalho, desenvolver-lhe o espírito de iniciativa, a curiosidade de descobrir, a originalidade.

Dar o abalo inicial e deixar marchar a onda, repetir a impulsão tantas vezes quantas fôr necessario." (PAES, 1908, p. 45)

é exemplar, mas não é única. Atente-se nas palavras de Ruy Luís Gomes a respeito da época em que Bento de Jesus Caraça (1901-1948) estudou (início da década de vinte do século passado):

“(...) pertenceu a uma geração que fez a sua própria preparação, no domínio da Matemática, numa época em que as nossas Escolas Superiores estavam inteiramente informadas pelo velho e desastrado conceito de que se pode ser um grande professor universitário sem nunca se ter patenteado, na análise exaustiva de algum problema concreto, a garra ou, pelo menos, o sentido de investigador." (GOMES, 1949) 
Também Vicente Gonçalves se refere, de modo indireto ao ensino em Portugal, no seu tempo de estudante universitário, focando mais uma vez a ausência quase total de investigação por parte dos professores universitários e as consequências que daí advinham para a formação dos jovens alunos universitários:

"A esse tempo, quase por toda a parte se viam as universidades, assistidas de Institutos onde o escol intelectual ajudava a refundir $e$ dilatar a ciência que àquelas incumbia divulgar. Raras se resignavam à subalternidade da mera transmissão de conhecimentos vindos do passado ou de além fronteiras; em quase todas, velhas ou moças, se sentia aquela vibração criadora que denuncia nas nacionalidades (e nos indivíduos) a maioridade científica." (GONÇALVES, 1948)

Sidónio Paes, ainda que essencialmente político, não conseguiu fazer vingar as ideias reformadoras e modernas que tinha para o ensino universitário. Francisco Gomes Teixeira (1851-1933), já nos finais do século XIX, Aureliano de Mira Fernandes (18841958) e José Vicente Gonçalves (1896-1985) são os três professores universitários que se destacam no panorama matemático português da primeira metade do século XX.

Qualquer um destes matemáticos, na sua época, fazia investigação em temas de interesse da comunidade matemática internacional e ao nível dos seus congéneres estrangeiros, sendo reconhecidos pelos seus pares. Tiveram também um papel essencial no incentivo à investigação junto dos seus alunos e de colegas mais jovens, em particular, Teixeira e Gonçalves com a criação de jornais científicos que permitiam a divulgação da investigação feita em Portugal junto da comunidade científica estrangeira e vice-versa.

A década de 40 do século XX, mais conturbada por questões políticas, afasta grande parte dos jovens matemáticos que a geração anterior de professores se esforçou por formar de modo mais moderno e dando especial relevo à preparação para investigar. Tendo em conta o percurso brilhante, que está estudado e documentado, de muitos matemáticos da designada geração de 40, entre eles Ruy Luís Gomes (1905-1984), António Aniceto Monteiro (1907-1980), Hugo Ribeiro (1910-1988), Alfredo Pereira Gomes (1919-2006), José Morgado Jr. (1921-2003), podemos concluir que a formação inicial recebida nas Universidades de Coimbra, Lisboa e Porto foi de qualidade.

Em Portugal, na segunda metade do século XX, destacamos António Almeida e Costa (1903-1978) e José Sebastião e Silva (1914-1972), podíamos fazê-lo por várias razões, escolhemos o facto de ambos terem formado escola nas suas áreas de investigação de eleição, respetivamente, Álgebra Moderna e Teoria das Distribuições (Cosme \& Costa, 2015).

Detalhamos em seguida o caso de Vicente Gonçalves.

\section{Um estudo de caso: José Vicente Gonçalves}

José Vicente Martins Gonçalves nasceu no Funchal, na ilha da Madeira e faleceu em Lisboa. Foi professor universitário durante a primeira metade do século XX, mais precisamente, de 1917 a 1967. O seu percurso profissional divide-se por três grandes 
instituições portuguesas do ensino superior: Universidade de Coimbra, Universidade de Lisboa e Instituto Superior de Ciências Económicas e Financeiras.

Este professor tem um comportamento atípico para professor universitário português (de ciências matemáticas) do início do século XX.

Dos estudos desenvolvidos (por exemplo (Costa, 2001, 2007)) sobre a vida e obra desta personalidade da comunidade matemática portuguesa, defendemos que Vicente Gonçalves teve um papel de relevo na mudança de "postura" do professor universitário do início do século XX. Identificámos três vertentes na sua atuação, a de professor, a de investigador e a de autor (no sentido de ter preocupações em publicar e divulgar os seus trabalhos) que se sustentam umas às outras de modo cíclico.

A conjugação destas vertentes dá forma a uma identidade profissional pouco comum na época, em Portugal. Dias Agudo, seu antigo aluno, nas palavras que se seguem, carateriza de forma muito clara o profissionalismo de Vicente Gonçalves:

“(...) numa época em que, entre nós, a dedicação exclusiva à profissão estava muito longe do que agora é habitual, ele [Vicente Gonçalves] sempre optou por dedicar toda a vida à criação da ciência e transmissão do saber." (AGUDO, 1987)

\subsection{Caracterização de Vicente Gonçalves como professor}

Vicente Gonçalves lecionou principalmente cadeiras do $1 .^{\circ}$ ano, entre outras, Cálculo Infinitesimal, Álgebra Superior e Matemáticas Gerais. A preparação da aula incluía a escolha e encadeamento dos temas, a seleção e refinamento das demonstrações, a escrita dos sumários, a redação e atualização de textos de apoio. Dava orientações aos seus assistentes e, mesmo nos exames (orais), procurava ensinar.

Procedia à atualização dos cursos. Tinha o hábito de incluir temas recentes de investigação nas suas lições, de referir Matemáticos portugueses e o seu trabalho e de indicar as referências bibliográficas de que fazia uso (remetendo os alunos para a consulta das fontes). Estes aspetos sugerem uma intenção de familiarizar os alunos com o meio científico-matemático da época.

As suas aulas eram lições magistrais, verificando-se, em geral, um desfasamento entre o nível de exposição e a bagagem científica dos alunos.

\subsection{Caracterização de Vicente Gonçalves como investigador}

Vicente Gonçalves desenvolvia estudos de investigação em tópicos matemáticos recentes à data e de interesse também de matemáticos estrangeiros. Correspondia-se com vários, entre eles, Evelyn Frank, A. Ostrowski, Paul Montel, Oskar Perron e Konrad Knopp.

Os seus artigos estão escritos, maioritariamente, em francês e, embora publicados em revistas científicas nacionais, eram conhecidos e citados por matemáticos estrangeiros. Alguns dos artigos contêm contributos relevantes para o avanço do assunto em estudo.

Participou em vários congressos científicos.

Incentivava os seus colegas mais jovens, muitas vezes seus ex-alunos, a investigar. 
Vicente Gonçalves tinha a particularidade de investigar temas que surgiam da preparação cuidada que fazia das suas lições, é nesse sentido que vão as palavras seguintes de Costa e Vitória (1997): "Existia uma proximidade temporal entre a matemática que o matemático Vicente Gonçalves fazia (e conhecia) e a que o professor Vicente Gonçalves ensinava".

\subsection{Caracterização de Vicente Gonçalves como autor}

Vicente Gonçalves foi dos primeiros matemáticos a escrever manuais para o ensino superior e para o ensino liceal. Eram textos rigorosos, completos e muito ricos no sentido de terem notas históricas, referências bibliográficas e tópicos recentes de investigação (no caso dos manuais para o ensino superior). Os seus textos estão escritos com rigor, clareza e precisão matemática. Não são textos fáceis.

O Curso de Álgebra Superior é considerado um tratado ao nível dos que se faziam na europa à data; é citado e valorizado por vários matemáticos portugueses e estrangeiros.

Os seus cerca de 100 artigos distribuem-se, essencialmente, por três áreas da matemática: a Análise, a Álgebra e a História da Matemática e estão quase todos referenciados na Zentralblatt e/ou na Mathematical Reviews.

Vicente Gonçalves deixou textos de dois tipos: literários e científicos. Subjacente a ambos está a sua formação clássica e um estilo próprio.

\section{Síntese final}

Vicente Gonçalves - na sua atividade de professor universitário - dava atenção a três vertentes, à docência, à investigação e à publicação dos seus textos (figura 2). Vertentes que se tornaram norma, em Portugal, na segunda metade do século XX.

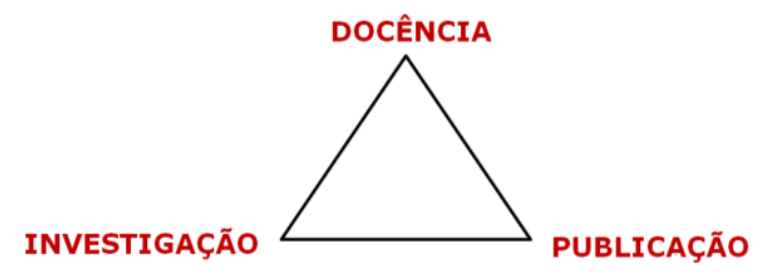

Figura 2 - Modelo da atuação de Vicente Gonçalves como professor universitário (1. ${ }^{\text {a }}$

metade do séc. XX)

Tinha ainda a particularidade de conseguir interligar estas vertentes de forma harmoniosa e fecunda: “(...) a docência de Vicente Gonçalves era vivificada pela seiva da actividade de investigação e esta motivada, em grande parte, pelo seu interesse em 
aprofundar, melhorar e tornar mais estimulante o ensino." (Jesus, 1997). Ambas acompanhadas pela sua preocupação em publicar e divulgar os seus textos.

Este tipo de opção, menos vulgar, não o impediu de ser reconhecido e respeitado pelos seus pares, muito pelo contrário; em (Costa \& Malonek, 2011) fundamentamos esta afirmação.

Com a sua atuação, Vicente Gonçalves contribuiu fortemente para mudar o ensino universitário português, para criar uma identidade profissional de professor universitário e para a criação de uma geração de jovens investigadores matemáticos e economistas de reconhecido mérito, muitos dos quais ainda fazem parte da elite intelectual do país.

\section{Bibliografia}

AGUDO, F.R. Dias. (1987). Resposta do Académico F.R. Dias Agudo ao Académico J. Tiago de Oliveira. In: Memórias da Academia de Ciências de Lisboa (Classe de Ciências) n. ${ }^{0}$ 28. 225-232.

COSME, Catarina \& COSTA, Cecília. (2015). Creating and Developing a Mathematical Research School in a Peripheral Country: The Case of Norms Having Matrix Values. In: Applied Mathematical Sciences, vol. 9, n. ${ }^{\circ}$ 32. 1597-1605.

COSTA, Cecília. (2001). José Vicente Gonçalves: Matemático... porque Professor!, (Colecção Memórias n. ${ }^{\circ}$ 37). Funchal: Centro de Estudos de História do Atlântico, Secretaria Regional do Turismo e Cultura. [Adaptação da tese de doutoramento de 2000].

COSTA, Cecília. (2007). Males do ensino superior" - a opinião de J. Vicente Gonçalves em 1930. In: Revista Brasileira de História da Matemática, vol. VII, n. ${ }^{\circ}$ 14. 155-162.

COSTA, Cecília \& MALONEK, Helmuth. (2011). Testemunhos de reconhecimento: cartas de Oskar Perron e Konrad Knopp a Vicente Gonçalves. Atas do V Encontro LusoBrasileiro de História da Matemática. Castelo Branco, Portugal.

COSTA, Cecília \& VITÓRIA, José. (1997). Nótula sobre Zeros de Polinómios. In: Boletim da Sociedade Portuguesa de Matemática, n. ${ }^{\circ}$ 37. 21-34.

GOMES, Ruy Luís. (1949). Bento de Jesus Caraça Grande Educador. In: Gazeta de Matemática, ano $\mathrm{X}, \mathbf{n}^{\circ} \mathbf{4 1} .4$.

GONÇALVES, José Vicente. (1948). Espírito utilitário. In: Ciência (Rev. da A.E.F.C.L.) vol. I, n. ${ }^{\circ}$ 1. 9-11.

JESUS, Fernando. (1997). O Mestre também ensinou no ISCEF. In: Boletim da Sociedade Portuguesa de Matemática, n. ${ }^{\circ}$ 37. 41-46.

PAES, Sidónio. (1908). Oração de sapiência recitada na sala grande dos actos da universidade, no dia 16 de Outubro de 1908. In E. G. Mariano (Comp.) Faculdade de Ciências e Tecnologia da Universidade de Coimbra Orações de Sapiência Século XX (pp. 37-50). Coimbra: Faculdade de Ciências e Tecnologia da Universidade de Coimbra. 
O professor universitário português do início do século XX...

\section{Cecília Costa}

Departamento de Matemática - UTAD - Vila Real

- Portugal

E-mail: mcosta@utad.pt 